\title{
LEVANTAMENTO E ANÁLISE DA BIBLIOGRAFIA DOS PRINCIPAIS CURSOS DE COMUNICAÇÃO NO BRASIL
}

Marcela Regina Guérrer Barrios Marino, Rogerio do Amaral

Universidade do Oeste Paulista - UNOESTE. Curso de Comunicação Social: Jornalismo/Publicidade e Propaganda, Presidente Prudente -SP. E-mail: marcelabmarino@gmail.com

\section{RESUMO}

A presente pesquisa teve como objetivo proceder a um levantamento do referencial teórico das principais faculdades de Comunicação Social no Brasil e analisar a qualidade e a atualidade desse material em relação a algumas disciplinas oferecidas pelos cursos estudados. Para a execução dessa proposta, optou-se pelo procedimento quantitativo para o levantamento do referencial teórico e o emprego da pesquisa qualitativa na análise do material. Quanto aos resultados encontrados, a comparação permitiu verificar que o curso de Comunicação Social da Facopp oferece aos seus alunos o mesmo conteúdo oferecido por outras importantes instituições de Comunicação no país. Devido a essa atualidade do conteúdo oferecido pela instituição, no que tange a mudança de grade do curso da Facopp, as sugestões de mudanças são pequenas e estão atreladas mais a carga horária das disciplinas do que ao conteúdo discutido por estas matérias.

Palavras-chave: Plano de ensino; Grade curricular; Carga Horária; Bibliografia; Comunicação Social

\section{SURVEY AND ANALYSIS OF THE LITERATURE OF MAIN COURSES COMMUNICATION IN BRAZIL}

\begin{abstract}
This research aimed to conduct a survey of the major theoretical schools of Social Communication in Brazil and analyze the quality and the contemporaneity of this material for some subjects offered by the courses studied. To implement this proposal, we opted for the quantitative procedure for lifting the theoretical framework and the use of qualitative research in the analysis of the material. As for results, the comparison has shown that the course of Social Communication Facopp offers its students the same content offered by other major institutions of communication in the country. Due to this actuality of content offered by the institution, regarding the change of grade of the course of Facopp, the suggested changes are small and are more tied to the amount of teaching time to the content discussed in these subjects.
\end{abstract}

Keywords: Plan of education; Curricular grade; Credit Hour; bibliography; Social communication 


\section{INTRODUÇÃO}

Este artigo apresenta como temática a bibliografia utilizada em disciplinas oferecidas por alguns cursos da área de Comunicação Social, na habilitação de Jornalismo e de Publicidade e Propaganda, em comparação com o referencial indicado pela Faculdade de Comunicação Social “Jornalista Roberto Marinho" de Presidente Prudente (Facopp), da Universidade do Oeste Paulista (Unoeste).

O objeto de estudo consiste na análise das ementas de disciplinas disponíveis nos portais acadêmicos dos cursos de Comunicação Social. Quanto à metodologia, a pesquisa procedeu a um levantamento dos planos de ensino das disciplinas selecionadas para análise; na sequência, identificou como tais disciplinas são oferecidas e distribuídas nas grades das faculdades; depois foi verificada a ementa dessas disciplinas e a classificação de sua proposta de acordo com as três fases dos cursos de comunicação no país: clássico-humanística; científico-técnica e crítico-reflexiva. Por fim, analisou-se as referências bibliográficas empregadas nessas disciplinas, observando a relevância das obras para a área, a atualidade da obra e a relação entre a obra e a disciplina. Os cursos de Comunicação Social escolhidos para a área do Jornalismo foram a Universidade de São Paulo (USP); a Universidade Estadual do Rio de Janeiro (UERJ); a Faculdade Mackenzie; e, a Universidade do Vale do Rio dos Sinos (Unisinos). Já para a área de Publicidade e Propaganda foi selecionada a Universidade de São Paulo (USP); a Universidade Federal do Paraná (UFPR), a Faculdade Mackenzie; e, a Universidade do Vale do Rio dos Sinos (Unisinos).

Quanto à justificativa, a pesquisa mostrou-se procedente, principalmente, porque a Facopp encontrava-se num momento de transição da grade curricular. Com isso, novas disciplinas são inseridas na grade, assim como as disciplinas da grade anterior passarão por uma reciclagem para atualização do referencial teórico. Diante desse quadro, uma pesquisa que possibilitasse o conhecimento do referencial teórico e das ementas das principais faculdades do país permitiria à Facopp oferecer um conteúdo atual em sua nova grade.

\section{O Ensino de Comunicação no Brasil}

A história do ensino da Comunicação surge como necessidade emergente de uma sociedade em desenvolvimento. No início do século XIX, Helbert Spencer (1820-1903) entende a comunicação como um sistema orgânico que integra a sociedade industrial com as multidões humanas, gerindo essa relação complexa. Acreditava-se que a comunicação irradiava o conceito de massa do centro do 
poder (sociedade industrial) à periferia. Fernand Braudel, historiador, cita as primeiras formulações das teorias difusionistas, onde os conceitos de sociedade de massa e difusão em massa através da comunicação se esclarecem, uma vez, que essa teoria parte do princípio que o progresso só atinge os arredores através da irradiação de valores do centro, "sociedade industrial". Sendo assim, no início do século XX, aparecem os primeiros cursos de comunicação na Europa e nos Estados Unidos da América que foram agrupados no segmento das "ciências sociais aplicadas" (MCQUAIL, 1994). Seus quadros de referência estavam centralizados no sistema produtivo dos meios de comunicação e foram rotulados pelos filósofos da Escola de Frankfurt como “indústria cultural” (HORKHEIMER; ADORNO, 1971).

Estando os primeiros cursos inseridos nas universidades, esse ambiente permitiu que os estudantes circulassem tanto em áreas das ciências básicas (sociologia, história e antropologia), como das ciências humanas (filosofia, artes, literatura). Essa formação mesclava o aprendizado tecnicista herdado das necessidades da sociedade industrial com a compreensão das teorias relativas aos efeitos sócio-culturais dos sistemas midiáticos. No Brasil, a necessidade da criação de cursos de Comunicação começa a partir do desenvolvimento fabril nas décadas de 1920 e 1930 . Somente em 1943, o Decreto-lei no 5.480, torna oficial o ensino superior de Jornalismo Impresso. E somente em 1951, foi criada a Escola de Propaganda do Museu de Arte de São Paulo. De acordo com Pinto (2003), esse surgimento aconteceu devido ao crescimento constante da demanda por profissionais qualificados para atuar nas multinacionais que se instalavam no País, o crescimento do processo de industrialização e acirramento da concorrência e dos meios de comunicação existentes.

O interesse das multinacionais por esses profissionais foi um dos fatores que exerceu pressão para as escolas de jornalismo se tornarem escolas de Comunicação. O ensino superior nas áreas de Jornalismo e Publicidade no Brasil, depois unificados pela nomenclatura de Comunicação é, notoriamente, influenciado pelos interesses econômicos e políticos e pelo crescimento industrial vigentes, assim como na Europa e Estados Unidos da América. Em meio à tensão e instabilidade política que o Brasil atravessava em 1962, o Governo Federal instituiu um currículo mínimo a ser seguido pelo Ensino Superior. A falta de professores com titulação específica na área de jornalismo cedeu lugar para professores com formação humanística e afastou a possibilidade de um ensino focado na crítica da realidade social (PINTO, 2003). Em 1966, o currículo mínimo do curso de Jornalismo foi alterado novamente para atender aos interesses políticos e empresariais e tinha uma inclinação tecnicista. Três anos mais tarde, em 1969 esse currículo do curso de Jornalismo foi 
novamente modificado para o currículo mínimo do curso de Comunicação Social com habilitação em Jornalismo, Publicidade e Propaganda, Relações Públicas e Editoração.

O currículo de Jornalismo, que gozava de certa tendência tecnicista, passa a contar com as alterações previstas no novo mínimo, que apresenta como foco o ensino profissionalizante (SILVA, 1979) e justamente essa é a base do currículo da habilitação de Publicidade e Propaganda. Dessa maneira, a habilitação nasce com viés técnico profissionalizante. Segundo Marques de Melo (1979), a maioria das instituições tinha instalações precárias, utilizavam literatura estrangeira e técnicas que não podiam ser aplicadas em ambiente acadêmico, impedindo a criticidade e a criatividade por parte de professores e alunos.

Em 1977, o Conselho Federal de Educação (CFE) decide pela reformulação do mínimo, que passa a ser ainda mais centralizador. O documento apresenta, assim, não somente as disciplinas que deveriam integrar o currículo, mas também, traz as ementas das matérias, com o apontamento do conteúdo básico a ser adotado pelas instituições. Em janeiro de 1984 é publicada a Resolução 02/84 que fixa o currículo mínimo do curso de Comunicação Social. Sobre esse mínimo, Marques de Melo (1998) pondera sobre as consequências na prática.

[...] cabe referir ao exagero das 'ementas' fixadas para todas as disciplinas do currículo. Uma quase prisão destinada aos docentes, suprimindo a 'liberdade de cátedra'. Também isso foi contornado. $O$ 'controle' institucional é inviável dentro da sala de aula. A maioria dos professores manteve fidelidade às ementas somente no 'papel', ou seja, nos programas arquivados na secretaria do curso. Mas nas classes ministraram livremente os conteúdos preferidos. (MARQUES DE MELO, 1998, p. 17).

Em 1996, a lei de Diretrizes e Bases da Educação (LDB), extingue o currículo mínimo. De 1997 a 2001 existe um “vazio” legal. Em 2002 passam a vigorar as novas Diretrizes Curriculares da área de Comunicação Social e suas habilitações, que propõe a flexibilização da estruturação do curso, considerando realidades regionais e transformações da área, além de orientações de um padrão de qualidade. Foram contemplados no documento o perfil comum dos formandos, perfis específicos por habilitação, as competências e habilidades gerais e, também, as específicas por habilitação, conteúdos básicos e específicos, orientações sobre estágio, atividades complementares, estrutura do curso, acompanhamento e avaliação, além de permitir a criação de novas habilitações.

A extinção dos currículos mínimos representa uma grande abertura para a reflexão sobre a concepção dos projetos pedagógicos para o curso de Comunicação Social. Após período de centralização excessiva, projetos inovadores passam a ter espaço. Torna-se possível, então, o tão 
almejado diálogo com as realidades regionais. Há maior liberdade para a construção das matrizes curriculares, bem como a sua contínua revisão face às aceleradas transformações que caracterizam o campo comunicacional.

\section{Análise de Grades Curriculares da Área de Comunicação Social}

Quanto à carga horária, o conteúdo da disciplina de metodologia de pesquisa na Facopp é oferecido em duas disciplinas que estão dispostas na grade no terceiro e quarto termos. Cada disciplina apresenta uma carga horária de duas horas semanais. A partir da comparação com as universidades citadas acima, percebe-se que a Facopp oferece a disciplina nos mesmos moldes, já que a predominância é para que essas disciplinas sejam ofertadas em média de quatro horas semanais e nos termos iniciais da graduação. No que se refere às disciplinas de língua portuguesa, esse trabalho comparou as universidades UFPR, UERJ. Mackenzie, Unisinos e USP, com as disciplinas da Facopp, ao final considerando que a grade da Facopp, oferece língua portuguesa, com especificidades para as habilitações, em relação as universidades citadas aqui, nota-se que existe uma carga horária excessiva para língua portuguesa, já que o curso da Facopp, em média tem o dobro de carga horária para disciplinas de língua portuguesa.

Para a área de marketing, a Facopp apresenta três disciplinas divididas entre marketing e mercadologia, oferecidas na habilitação de Publicidade e Propaganda do quinto ao sétimo termo, com carga horária de duas horas semanais. A comparação feita nos permite depreender que a carga horária para a disciplina de Marketing empregada na Facopp é relativamente baixa, pois em comparação com outras faculdades brasileiras percebe-se que essa área é trabalhada numa carga horária dobrada e até mesmo quadriplicada. Sobre os Projetos Experimentais, a totalidade dos cursos pesquisados exige o Projeto Experimental, embora seu formato se diferencie entre Estudo de Caso, Trabalho Prático acompanhado de fundamentação teórico-conceitual ou Monografia. O tempo dedicado para realização do mesmo é diferente, com carga horária variando entre 240 e 300 horas.

Quanto ao tipo de ênfase dada aos cursos de comunicação no Brasil, no que se refere à abordagem de ensino adotada, par metodologia de pesquisa, a relação estabelecida entre as fases de estudo da comunicação social no Brasil e as propostas das ementas das disciplinas mostram o predomínio de um caráter tecnicista, com o foco dos estudos centrados na apresentação dos instrumentos e das regras necessárias para a produção de um trabalho científico. A exceção, nesse caso, refere-se aos cursos da USP, que seguem a linha da universidade e propõe a apresentação de 
disciplinas de cunho reflexivo, preocupadas em discutir as contribuições que tal disciplina pode oferecer à sociedade. Quando analisadas as ementas das disciplinas de língua portuguesa, nota-se que essas disciplinas transitam entre os dois focos de ensino, porém há uma incidência maior de um ensino crítico-reflexivo, pois a construção de uma linguagem deve sempre ser capaz de compreender o contexto em que ela se cria, permitindo aos leitores dessa linguagem entender o que se passa no universo do produtor textual

Quanto à área de Marketing, comparando as ementas das instituições pesquisadas com a Facopp, nota-se que existe literalmente uma repetição dos temas abordados nas disciplinas, tanto na parte prática quanto na teórica. A abordagem contextualizada, assim como a preocupação com a aplicação dos conceitos permeia todas as ementas e, é relevante o destaque dado à disciplina de Promoção de Vendas e Merchandising que aparece em quase todos os cursos analisados. Tal postura leva-nos a entender uma abordagem prescritiva dos manuais e documentos oficiais, por parte dos professores das disciplinas acima mencionadas. Já nos Projetos Experimentais, a análise das ementas permite verificar que $\mathrm{O}$ amadurecimento metodológico é o principal ponto de convergência, tendo a publicidade como elemento central.

Por fim, a análise do referencial teórico norteou-se em verificar a relevância da obra e do autor para a área de estudo, a atualidade da obra e a relação entre o conteúdo e a proposta das disciplinas. Assim, em Metodologia de Pesquisa percebe-se que os autores empregados na Facopp seguem a linha da Mackenzie, da UERJ e da Unisinos (Duarte e Barros, Severino, Cervo e Bervian), com conteúdos metodológicos mais gerais e algumas obras específicas da área, com o objetivo de contemplar o proposto na ementa das disciplinas. Assim, tanto os autores como o material empregado é relevante e o material mostra-se atualizado. Nas disciplinas de língua portuguesa, o quadro levantado permite apreender que a Facopp segue a mesma linha das universidades estudadas, mostrando que os cursos de jornalismo e publicidade encontram-se atualizados no que tange o ensino de língua portuguesa no Brasil. Em Marketing, tem-se em comum o nome de um grande autor na área: Philip Kotler, seguido por nomes expressivos como Jerome McCarthy, John Westwood, Al Ries e Jack Trout, Regis McKenna e J. Graham Hooley e, também os brasileiros, Raimar Richers e Alexandre Las Casas. Na área de Mercadologia e/ou Promoção de Vendas é possível notarmos uma predileção pelas obras nacionais dos autores Regina Blessa, J. S. S. Ferracciu e Duda Pinheiro, dando crédito também a autores como Paco Underhill e M. Legran. A partir da análise realizada e tecendo uma comparação com o quadro bibliográfico adotado pela Facopp percebe-se 
que os autores empregados aqui seguem a linha da Mackenzie, Unisinos e Usp, com conteúdos metodológicos que contemplam o proposto na ementa das disciplinas. A maioria dos autores se repete de forma relevante e o material mostra-se atualizado.

No que se refere aos Projetos Experimentais, o amadurecimento teórico-metodológico é o principal ponto de agendamento para os estudos de mercado propostos pelo PEPP, o que torna necessário adentrar obras que permitam a reflexão sobre outras áreas como a política, sociologia e a psicologia como forma de superar os estudos meramente descritivos e quantitativos, o que vale para os futuros estudos na área de publicidade. O panorama de questões que motivam os estudos dos conteúdos bibliográficos contidos nas ementas dos cursos de Publicidade e Propaganda permite diagnosticar eixos de investigação e convergências, ao refletir as transformações que ocorrem tanto em ambientes acadêmicos como profissionais, onde os modelos tradicionais são questionados e aparecem experiências e padrões alternativos, redesenhando o mercado. Examinando os referenciais teórico-metodológicos dos PEPP's, será possível indicar um caminho que nos leve a renovação dos modelos atuais.

\section{CONSIDERAÇÕES FINAIS}

Apesar das universidades escolhidas para a comparação se enquadrarem na proposta metodológica do trabalho, os autores não conseguiram avaliar as principais faculdades do país, segundo avaliação do último Enade, pois a maioria das faculdades brasileiras não disponibiliza em suas páginas na internet, os planos de ensino das disciplinas, o que limitou a análise a universidades que se encontram no mesmo patamar da Facopp, segundo o ranking do Enade. No entanto, os cursos investigados e comparados à Facopp apesar de não figurarem entre os principais cursos no ranking nacional de avaliação, pertencem a importantes faculdades brasileiras, o que na visão dos autores não atrapalha os resultados alcançados por esse trabalho. A verificação do referencial teórico foi construída a partir de outras duas análises preliminares, o estudo da carga horária das disciplinas investigadas e a construção da ementa dessas matérias. No que tange à carga horária, as disciplinas estudadas mostraram que a Facopp segue os parâmetros nacionais de distribuição de carga horária. A única ressalva dessa análise ficou por conta da disciplina de língua portuguesa, oferecida de maneira excessiva, mas que a reformulação da grade já indica a correção e adequação aos parâmetros das instituições investigadas. O estudo das ementas reforça essa característica da Facopp de acompanhar o perfil dos cursos de Comunicação oferecidos em outras instituições brasileiras tanto no que se 
refere ao currículo oferecido, como na predominância de um ensino de vertente tecnicista, com foco específico na apresentação de ferramentas que permitam aos futuros jornalistas e publicitários, participar do mercado de trabalho da área.

Por fim, o referencial teórico permitiu identificar que o curso da Facopp está atualizado quanto à teoria predominante na área trabalhando tanto os autores nacionais quanto os internacionais mais renomados em cada uma das áreas do conhecimento investigadas. Além disso, o referencial também se mostra atual, ou seja, os livros empregados nas disciplinas são edições lançadas nos últimos quinze anos. A exceção a esse período são as obras clássicas tão importantes na construção do conhecimento. Diante desse quadro, os autores notaram que esse trabalho torna-se relevante para que um curso possa se adequar à formação oferecida, lógico que sempre respeitando as particularidades do universo em que se encontra. Dessa forma, a sugestão é que novos trabalhos com esse foco possam ser desenvolvidos, no entanto, com a participação de mais professores, para dessa maneira contemplar cada vez mais disciplinas do curso. Os autores também perceberam que essa análise se tornaria mais completa, caso a investigação partisse da análise do projeto pedagógico dos cursos, item não realizado nesse trabalho, pois tal objetivo não foi elencado no início da investigação.

\section{REFERÊNCIAS}

HORKHEIMER, Max; ADORNO, Theodor W. Dialéctica del Iluminismo. Buenos Aires: Sur: 1971.

MARQUES DE MELO, José. Poder, Universidade e Escolas de Comunicação. In: MARQUES DE MELO, José; FADUL, Anamaria; SILVA, Carlos Eduardo Lins da (Orgs.). Ideologia e poder no ensino de comunicação. São Paulo: Cortez; Moraes/Intercom, 1979.

MARQUES DE MELO, José. Ensino de Graduação em Comunicação Social: paradigmas curriculares. Revista Brasileira de Ciências da Comunicação, ano XXI, n. 1, p. 13-23, jun. 1998.

MCQUAIL, Denis. Mass Communication Theory. 4. ed. London: Sage, 1994.

PINTO, Virgílio Noya. Comunicação e Cultura Brasileira. São Paulo: Ática, 2003.

SILVA, Carlos Eduardo Lins da. A política educacional brasileira e os currículos de Comunicação. In: MARQUES DE MELO, José; FADUL, Anamaria; SILVA, Carlos Eduardo Lins da (Orgs.). Ideologia e poder no ensino de comunicação. São Paulo: Cortez; Moraes/Intercom, 1979. 